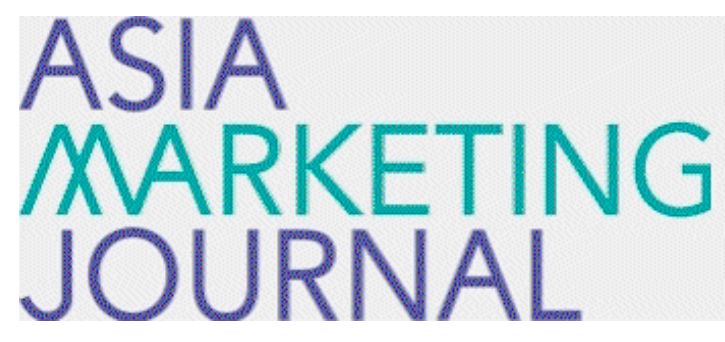

ASIA MARKETING JOURNAL

Volume 17 | Issue 1

Article 1

4-30-2015

\title{
A Study on Green Consumer Segmentation Based on Socio- Demographics and Behavioral Responses
}

Young Doo Kim

Follow this and additional works at: https://amj.kma.re.kr/journal

Part of the Marketing Commons

\section{Recommended Citation}

Kim, Young Doo (2015) "A Study on Green Consumer Segmentation Based on Socio-Demographics and Behavioral Responses," Asia Marketing Journal: Vol. 17 : Iss. 1 , Article 1.

Available at: https://doi.org/10.15830/amj.2015.17.1.1

This Article is brought to you for free and open access by Asia Marketing Journal. It has been accepted for inclusion in Asia Marketing Journal by an authorized editor of Asia Marketing Journal. 


\section{A Study on Green Consumer Segmentation Based on Socio-Demographics and Behavioral Responses: Renewing the Relationships between Socio-demographics and Green Behavior*}

In the $21^{\text {st }}$ century, green consumer behavior, playing one of the core roles of sustainability, is still an important issue to green-related stakeholders. Because one of the major objectives of green-consumer research is an improvement of behaviors aligned with greening, this paper revisited socio-demographic variables and shed light on segmenting and profiling green consumers based on their connectedness between socio-demographic variables and green behaviors. Using correlations, factor analysis, analysis of variance, $\mathrm{k}$-means cluster analysis and $\chi^{2}$-tests, this paper shows that socio-demographic variables differentially impact green-consumer behaviors. In order to profile green consumers, this paper additionally attempts to segment green-consumer groups. The results also coincide with former findings that socio-demographic variables relate significantly with segmented green-consumer group behaviors.

General findings are summarized as: 1) older people used green practices more strongly than younger people, 2) females demonstrated better energy-saving and recycling practices compared to males, 3) marital status also significantly influenced green-related behaviors, 4) subjective social class had a significant influence on green-related behaviors, 5) education level and income, however, weakly influenced or showed no impact on green-related behaviors, and 6) a green consumer was classified as an 'active green consumer,' 'utilitarian green consumer,' or 'inactivated green consumer.' The utilitarian green consumer group distinctively behaved more strongly in energy-saving and recycling practices compared to the inactivated green consumer group, whereas active green consumers behaved more strongly on the whole, when compared to those in the inactivated green consumer group.

Key words: green consumer, segmentation, socio-demographics, behavioral response, k-means cluster analysis

* This study used "2013 Consumption Life Indicators in Korea" from Korea Consumer Agency(KCA).

** Assistant Professor, Department of Business Administration, Hansei University (ydkim@hansei.ac.kr) 


\section{Introduction}

Growth of green or potential green-oriented consumers has emerged and developed with the spotlight recently shifting to environmental concerns, social well-being, and economic crises or development. In the 1990s, Korea Consumer Agency, surveyed consumption consciousness, reported that approximately $45 \%$ of respondents expressed they were willing to purchase more expensive products for preventing environmental pollution (Korea Consumer Agency 1993). Current data, meaning that of the 2010s, surveyed nationwide subjects on self-reported measures, with approximately $63 \%$ of the Korean subjects reporting to be practice green life (Statistics Korea 2013).

With growing demands for greenness, it seems that the focus on greening has been altered. Leonidou and Leonidou (2011) pointed out that green-management themes, with the extent of consumer subjects, have focused on consumers (e.g., green markets, segments, and consumers) and global-market mechanisms since the 1990s, coupled with air pollution and ecologically- and socially-concerned consumers emerging in the 1960s. do Paço et al. (2009) was also insistent on similar viewpoints. These views held that green-related issues have been relatively fixed on consumer demands for pro-environmental products since the 1990s, whereas the focus was more on energy conservation in the 1970s and 1980s when green products were limited in their availability.

Research on green consumers, aligned with green marketing, has uncovered a variety of scopes such as the environment, food, health, energy saving, and recycling (Culiberg 2014; do Paço and Varejâo 2010; Iyer and Kashyap 2007; Kinnear et al. 1974; Taylor and Todd 1995). Some researchers have, therefore, pointed out that green-related studies must show a pluralistic viewpoint (do Paço et al. 2009). do Paço et al. (2009), however, also pointed out that one of the main subjects in green-related studies is market segmentation and profiling of green consumers.

In green consumption and green marketing, market segmentation and profiling have distinctively important meanings. Greening is deeply related to strategy and (public) policy. It is, therefore, an academically and practically useful theme because it differentiates consumers based on their sensitivities to green-related variables.

Segmentation and profiling of green consumers have used a variety of variables, including psycho-graphics (e.g., value, attitude, motivation, personality, life-style), and socio-demographic variables (e.g., age, gender, income, social class, occupation, marital status). Socio-demographic variables, though their explanatory power has weakened, remain important for green-consumer segmentation criteria and fostering effective policy instruments related to green consumers 
(Akehurst et al. 2012). For several reasons, sociodemographic variables have endured as profoundly researched elements in green consumption. First, as mentioned above, green-consumer issues are deeply related to stakeholder policies. Second, one of the major objectives of green-consumer research is an improvement of behaviors aligned with greening (e.g., improving the adoption of green products or services).

Individuals, however, did not adopt green products in comparing their value, attitude, or behavioral intentions toward them (Claudy et al. 2013; Kalafatis et al. 1999; Mostafa 2007). Therefore, it is important to reappraise the connectedness between green behaviors and socio-demographics, which were measurable, practically actionable and traditionally investigated variables. Surprisingly, there are only a few nationwide green studies - especially focusing on the relationship between socio-demographic variables and green behaviors - that have reported on green practices in the Republic of Korea, though some researchers reported on a myopic range of age groups such as university students (e.g., Kim 2014).

This study aims to investigate the determinants of greening practices by analyzing greenconsumer segmentation and profiling focused on socio-demographic and behavioral variables. Moreover, the paper suggests effective greenconsumer policies based on the findings of empirical green-consumer segmentation and profiling.

The following literature review concentrates on green consumers, green-consumer segmentation, and profiling performed, and presents suggestions for effective green-consumer marketing and public policy.

\section{Theoretical Background}

\subsection{Green-Consumer Behaviors}

In its initial stages, the study of green consumer behavior was focused on environmental awareness. Studies on green consumer behavior were largely concerned with environmental problems such as pollution, energy conservation. The interest in green consumers then migrated to societal consciousness and social well-being, with environmental concerns simultaneously considered (Prothero 1996). At that time, green consumer behavior as a driver of greening emerged more remarkably than ever before (Kalafatis et al. 1999). Nowadays, green consumers play a key role in sustainable practices, which links to global sustainability. For example, Peattie and Charter (2003) linked concerns for green consumption to the quality of life and sustainable development of society. Sustainable consumption for green consumers is a pivotal part of sustainable development (Abeliotis et al. 2010).

Because greening is a global issue and green consumers play a major role in the matter, studies on green consumers have been reported 
worldwide (see Diamantopoulos et al. 2003; Hughner et al. 2007; Verain et al. 2012) as well as Republic of Korea (Joung, Park, and Ko 2014; Jung and Cho 2014; Kim 2014; Shin and Shin 2012). A limited but recently incremental number of studies reported cross-national comparisons of green-consumer behavior (Chan and Lau 2002; Hori et al. 2013; Polonsky et al. 2014).

Research on green consumers, aligned with green marketing, has uncovered a variety of scopes. More specifically, the study of green consumers has included pro-environmental or environmentally-friendly values, attitudes and behaviors such as ecologically-conscious consumer behaviors (Kinnear et al. 1974; Verain et al. 2012; Webster 1975), and a focus on environmental preservation centered on matters such as global warming, fossil fuels depletion, energy saving and utilizing forms of green energy (Corradi et al. 2013; do Paço and Varejâo 2010; Sütterlin et al. 2011; Sweeney et al. 2013), recycling (Culiberg 2014; Davies et al. 2002; Iyer and Kashyap 2007), and garbage reduction (Taylor and Todd 1995), and a focus on healthy life such as purchasing organic food (Chan and Lau 2002; Cicia et al. 2002; Davies et al. 1995; Hughner et al. 2007).

Although many consumers expressed themselves, according to self-reports, as being deeply concerned with the environment, they did not buy as many pro-ecological products as their reports would indicate (Kalafatis et al. 1999), that is to say that a distinct attitude-behavior gap exists related to purchasing pro-environmental products and other green-related behavior as well (Claudy et al. 2013; Mostafa 2007). Because one of the major objectives of green-consumer research is an improvement of green behaviors aligned with greening and sociodemographic variables are still important predictors in segmenting and profiling green consumers (Akehurst et al. 2012; Barr et al. 2005; D'Souza et al. 2007; Diamantopoulos et al. 2003; do Paço and Raposo 2010; do Paço et al. 2009; Gleim et al. 2013; Hughner et al. 2007; Kim 2014), it is an important issue to reappraise the connectedness between green behaviors and socio-demographics, which were measureable, practically actionable and traditionally investigated variables. From the perspective of marketers and public policy makers, the segmentation and profiling of green consumers involves predominantly important decisions. In order to effectively and efficiently operate public policy programs or implement a firm's marketing strategy, it is necessary for policy makers or marketing strategists to first suit their programs for targeted segments.

Green-consumer segmentation and profiling highlighted several behavioral-responsive variables. Commonly researched behaviors include buying behaviors, buying intentions, and willingness to pay (Balderjahn 1988; Chan 1999; Chan and Lau 2002; Cicia et al. 2002; Davies et al. 1995; Hughner et al. 2007). Consumers are usually 
classified by their buying quantities or buying experiences (e.g., heavy-user vs. light-user vs. non-user, buyer vs. non-buyer). For example, Chan (1999) classified green consumers as heavy or light green consumers based on their usage rates of green products.

Energy saving is another kind of green-practical behavior often mentioned in green literature (do Paço and Varejâo 2010; Hori et al. 2013; Sweeney et al. 2013). Recycling is also considered as a behavioral variable of green consumers (Culiberg 2014; Davies et al. 2002; Iyer and Kashyap 2007; Mainieri et al. 1997; Webster 1975). Some researchers investigated participation as a behavioral variable (Balderjahn 1988; Granzin and Olsen 1991; Mainieri et al. 1997), as Balderjahn (1988), for example, mentioned that the more environmentally-friendly attitude an individual held, the more he or she participated in the buying of green products. Mainieri et al. (1997) also mentioned that females (vs. males) probably participate more in recycling activities.

\subsection{Socio-demographic Studies on Green Consumers}

Socio-demographic variables have not only traditionally been utilized as (green-) consumer segmentation and profiling variables (Roberts 1996) but are also still important predictors in segmenting and profiling green consumers (Akehurst et al. 2012; Barr et al. 2005; D’Souza et al. 2007; Diamantopoulos et al. 2003; do Paço and Raposo 2010; do Paço et al. 2009; Gleim et al. 2013; Hughner et al. 2007; Kim 2014), even as their influence has somewhat weakened with equivocal findings being found between and within socio-demographic variables (Diamantopoulos et al. 2003; Roberts 1996; Straughan and Roberts 1999). For example, do Paço and Raposo (2010) found that age, education, income, and occupation were valid differentiating variables among green-consumer segments, whereas gender did not significantly differentiate these segments. Some researchers pointed out that the media is the reason the impact of socio-demographic variables on green consumers has weakened (Roberts 1996). While many consumers are simultaneously exposed to the same information via the same media, green consumers still feel that there is a lack of information (Glemm et al. 2013).

In spite of its limitations, segmentation and profiling based on socio-demographic variables is still important for research topics in green consumption for its advantages in effective accessibility and measurability.

Considering prior research, commonly mentioned socio-demographic variables are summarized as age, gender, education, and income, and additionally mentioned variables are occupation, social class, and marital status.

Age: One of the most easily identifiable variables in green consumption is age (Akehurst et al. 2012; Corradi et al. 2013; Diamantopoulos 
et al. 2003; do Paço and Raposo 2010; Hori et al. 2013; Joung et al. 2014; Kim 2014; Shrum et al. 1995; Straughan and Roberts 1999; Sütterlin et al. 2011; Webster 1975; for more details, see also Wiernik et al. 2013; Verain et al. 2012).

Some researchers reported that age had a significant effect on green behaviors (Abeliotis et al. 2010; Hori et al. 2013; D’Souza, Taghian, Lamb, and Peretiatko 2007; Jung and Cho 2014; Roberts 1996; Samdahl and Robertson 1989; Shin and Shin 2012; Straughan and Roberts 1999), whereas others reported that age had no relation to green behavior (Chen et al. 2014; Corradi et al. 2013; Kinnear et al. 1974). Among the findings of age-green behavior relations, although younger people tend to be more concerned with green issues than older people (Zimmer et al. 1994), multiple studies have demonstrated that older people practice green behaviors more often than their younger counterparts (Abeliotis et al. 2010; Hori et al. 2013; D’Souza, Taghian, Lamb, and Peretiatko 2007; Samdahl and Robertson 1989; Roberts 1996).

The mixed findings might be derived from measuring somewhat different dependent variables. For example, Kinnear et al. (1974) used ecological as a dependent variable, whereas Akehurst et al. (2012) used purchasing behavior.

When narrowly focused on the impact of age on green-consumer behaviors, older people tended to practice green behaviors more consistently than younger people (see Wiernik et al. 2013) and purchased organic products more often (Cicia et al. 2002). Barr et al. (2005) and Hori et al. (2013) found that age (weakly but) positively influenced energy-saving behaviors. Abeliotis et al. (2010) and Diamantopoulos et al. (2003) found that age was positively correlated with recycling activities.

H1: Age differentially influences practices of green behaviors. More specifically, older (vs. younger) people are more likely to practice green behaviors.

Gender: The bulk of studies reported relationships between gender and green-consumer behaviors (Brooker 1976; Kim 2014; Roberts 1996: Samdahl and Robertson 1989; Shin and Shin 2012; Shrum et al. 1995; Yam-Tang and Chan 1998; for more details, see Pinto et al. 2014). Ambiguous yet somewhat consistent findings between gender and green-consumer behaviors can be found. Some researchers reported no differences between females and males in participating in the conservation of natural resources (Mainieri et al. 1997) or in ecologically conscious consumer behaviors (Akehurst et al. 2012), while many others showed that females were more inclined to show environmental consciousness, intended to pay more for green products, and/or had more sustainable consumption intentions compared to males (do Paço and Varejâo 2010; Laroche et al. 2001; Pinto et al. 2014; Straughan and Roberts 1999), 
whereas males had a stronger intensive relationship between attitudes and use of environmentally-conscious products (Balderjahn 1988).

When focusing on the influence of gender on green-consumer behaviors, Davies et al. (1995) showed that females (vs. males) were more likely to purchase organic foods. do Paço and Varejâo (2010) found that females undertook more favorable behaviors for energy saving compared to males. Webster (1975) also reported that females (vs. males) had a significant relationship with the socially conscious consumer index (behavioral index). Diamantopoulos et al. (2003) found that females enacted recycling behaviors and green-purchasing behaviors more frequently than males. Mainieri and Barnett (1997) reported that females not only bought green products but also participated in recycling activities more often than males. Results show that females tend to be more idealistic energysavers than males (Sütterlin et al. 2011). And Jung and Cho (2014) showed that female (vs. male) actively purchased green products.

H2: Gender differentially influences practices of green behaviors. More specifically, female (vs. male) is more likely to practices green behaviors.

Education: Level of education, though controversial findings have been reported, has a positive impact on green-consumer behaviors (Akehurst et al. 2012; do Paço and Raposo
2010; Roberts 1996; Shin and Shin 2012; Shrum et al. 1995; Zimmer et al. 1994). It seems sensible that consumers with a higher level of education are more likely to take advantage of having greater environment-related knowledge, which would have a positive impact on greenconsumer behaviors. Nevertheless, it was found that education did not have a positive (Jung and Cho 2014; Kinnear et al. 1974; Mainieri et al. 1997) or negative (Samdahl and Robertson 1989; Straughan and Roberts 1999) impact on green-consumer behaviors.

When studying the influence of education on green-consumer behaviors, Granzin and Olsen (1991) reported that education and participation in environmental-protection activities had positive relationships. Webster (1975) found that education was a strong predictor for recycling activities, a finding also reported by Diamantopoulos et al. (2003). Sütterlin et al. (2011) also found similar results involving energy saving.

$$
\begin{aligned}
& \text { H3: Education levels differentially influence } \\
& \text { practices of green behaviors. More spe- } \\
& \text { cifically, the highly educated (vs. the } \\
& \text { less educated) is more likely to practice } \\
& \text { green behaviors. }
\end{aligned}
$$

Income: Income is also commonly mentioned as a variable related to green-consumer segmentation and profiling (Kassarjian 1971; Kinnear et al. 1974; Roberts 1996; Shrum et al. 1995; Zimmer et al. 1994). Many studies reported that 
price was a barrier to green consumption (Gleim et al. 2013). As a result, people may believe that, because green products are priced relatively high compared to traditional products, income has a great impact on green-consumer behaviors. Income also correlated with education. The results, however, have provided mixed findings, including a positive relationship between income and green consumption or behavior (Chen et al. 2014; do Paço and Raposo 2010; Henion 1972; Hori et al. 2013; Shin and Shin 2012), as well as a negative relationship (Abeliotis et al. 2010; Samdahl and Robertson 1989) or no relationship in some cases (Akehurst et al. 2012; Jung and Cho 2014).

When focused on the influence of income on green-consumer behavior, Webster (1975) found that higher family incomes (vs. lower family incomes) had a significant relationship with the socially conscious consumer index (behavioral index). Sütterlin et al. (2011) demonstrated that the third-highest level of four income classes showed relatively high energy-saving behavior, while Hori et al. (2013) found that income was only slightly positively influential on energysaving behaviors.

H4: Income differentially influences practices of green behaviors. More specifically, the higher (vs. the lower) the income is more likely to practice green behaviors.

Occupation: Occupation was another listed variable in several examples of green-related literature (D'Souza, Taghian, Lamb, and Peretiatko 2007; Joung et al. 2014; Shin and Shin 2014). Occupation significantly changed among greenrelated clusters (do Paço and Raposo 2010). For example, 'the uncommitted' segment mainly included service, sales, and administrative workers and students, whereas 'the green activists' segment included middle and senior management and specialists (Paço and Raposo 2010).

Occupation was significantly associated with consistent evaluation concerning green products (Yam-Tang and Chan 1998). For example, housewives were evaluated as being more consistently in line with their pre-purchase considerations (Yam-Tang and Chan 1998). This means that their actions followed their perceptions. Tilikidou (2007) showed that professionals revealed higher pro-environmental purchasing behaviors than other occupations.

\section{H5: Occupation differentially influences practices of green behaviors.}

(Subjective) social class: Social class was also found to be a common variable in green-related literature (Diamantopoulos et al. 2003; Iyer and Kashyap 2007). Diamantopoulos et al. (2003) found that social class significantly influenced recycling and purchasing behaviors, but social class was classified based on socioeconomic characteristics (see Diamantopoulos et al. 2003, table 2). In this paper, social class was 
classified based on the respondents' subjective perception, that is to say that it was a self-reported measure concerning the subjectively perceived class they belonged to. It was possible that if respondents perceived themselves as belonging to a higher social class, they would likely try to uphold social obligations.

\section{H6: Subjective social class differentially} influences practices of green behaviors. More specifically, the higher (vs. the lower) the subjective social class is more likely to practice green behaviors.

Marital status: Marital status was also found several green-related literatures (Joung et al. 2014; Laroche et al. 2001; Shin and Shin 2012; Yam-Tang and Chan 1998). Marital status significantly influences on willingness to pay more for pro-environmental products. Even though Diamantopoulos et al. (2003) found that unmarried people were inclined to undertake recycling behaviors more actively than married households, most of studies found that married status, compared to unmarried (single, separated, and divorced) status, has more willing to pay pro-environmental products (Laroche et al. 2001). Neuman (1986) also found that married people were more likely to practice green behaviors compared to single people.

H7: Marital status has an impact on practicing green behaviors. More specifically, married (vs. single) people are more likely to practice green behaviors.

\section{Research Methodology}

One of the main objectives of this study is to explore green-consumer segmentation and profiling based on practices of green behaviors using socio-demographic variables.

The data used in this study was supported from the "2013 Consumption Life Indicators in Korea" (for a more detailed description of the survey, see Hwang and Son (2013) “2013 Consumption Life Indicators in Korea”, conducted by the Korea Consumer Agency). Large and nationwide data and quota sampling generated from 1,500 respondents were collected. The survey participants were over 20 years. A structured questionnaire was used to investigate green-consumer segmentation and profiling. The research questionnaire, with an extensive list of green-related items, consisted of two major parts. Part I was composed of socio-demographic variables such as age, gender, occupation, life-cycle, education, income, and subjective social class (summarized socio- demographic variables were showed by table 2). Part II consisted of green-behavior practices. It reflected the purchasing of pro-environmental products, energy-saving, recycling, and practice initiation for green participation. 
This study is aimed at identifying the relationship between socio-demographic variables and practices of green behaviors and resulting, ultimately, in identifying types of green consumers. Verain et al. (2012) reported segments with regard to food and suggested that a broader perspective was needed to correctly understand green consumers. Therefore, based on prior research, practices of greening behaviors can be aggregated to four major sub-divisions such as purchasing pro-environmental products, energy saving, recycling, and initiating practices for green behaviors. These four items (Hwang and Son 2013) were measured on 5-point scales as respondents reported degrees of practice for each behavioral item ( $1=$ never practice, $5=$ always practice).

\section{Results of Socio-demographic Variables}

First of all, the correlations among practices for green behavioral items were analyzed. The results show that these items have significantly positive relationships $(p<.01)$ (see Table 1$)$. Next, exploratory factor analysis and reliability tests were executed. The results of the factor analysis, conducting the principal components method, show that all items loaded one construct and the factor loading value was at least .72, with the factor accounting for $61.07 \%$ of the total variance. Because it is greater than the cutoff value of .5 , it can be considered that the sampling for this dimension is adequate and all items commonly share certain properties, called 'practices for green behaviors.' The Kaiser-Meyer-Olkin measure was .74 and Bartlett's test of sphericity had a significance level of .001, meaning that the factor analysis was suitable. The results of reliability tests, Cronbach's a coefficient, were adequate (Cronbach's $a=.78)$ and indicated that items reliably inter-correlated with each other.

In order to investigate the relationships between socio-demographic variables and practices for green behaviors and resulting in segmented greenconsumer groups, this paper analyzed the influence of each socio-demographic variable on practices for green behaviors.

First of all, the influence of age on practicing

〈Table 1〉 Correlations among Practices for Green Behavioral Items

\begin{tabular}{c|c|c|c}
\hline Items & purchasing pro-environmental products & energy saving & recycling \\
\hline energy saving & $.495^{* * *}$ & & \\
\hline recycling & $.436^{* * *}$ & $.639^{* * *}$ & \\
\hline initiating green practice & $.467^{* * *}$ & $.415^{* * *}$ & $.424^{* * *}$ \\
\hline$* * * p<.01$ &
\end{tabular}


green behaviors was analyzed. Analysis was accomplished with high levels (the average of low level items: 'overall green practices') and low levels (each behavioral items) separately. The results demonstrate that age significantly influences overall green practices $(F=17.69$, $p<.01)$. Therefore, the hypothesis H1 was supported (see Table 2). And post-hoc analysis reveals that older (vs. younger) people (above 40 years) are more likely to practice green behaviors.

More specifically, age has a significant influence on purchasing pro-environmental products $(F=6.52, p<.01)$, energy saving $(F=11.12, p$ $<.01)$, recycling $(F=10.26, p<.01)$, and initiating green practices $(F=16.09, p<.01)$.

Next, the influence of gender on practicing green behaviors was analyzed. The results indicate that gender significantly influences on overall green practices $(F=8.51, p<.01)$ (see Table 2). Therefore, the hypothesis H2 was supported. Females (vs. males) are more likely to engage in green behaviors. Gender has a significant influence on energy saving $(F=8.30$, $p<.01)$ and recycling $(F=17.84, p<.01)$, whereas it shows no impact for purchasing pro-environmental products and initiating green practices.

The influence of education level on practicing green behaviors was analyzed. The results indicate that education level has no impact for overall green practices (see Table 2). More specifically, education level marginally significantly influences on the initiating green practices $(F=2.60, p=.05)$, whereas it shows no impact for the other items. Therefore, the hypothesis H3 was not supported by overall green behaviors, whereas it was partially supported by initiating green practices.

The influence of family monthly income on practicing green behaviors was analyzed. The results indicate that family monthly income has no impact for overall green practices (see Table 2). More specifically, family monthly income significantly influence on recycling $(\mathrm{F}=2.45, p$ $<$.05) and marginally significantly influences on the purchasing pro-environmental products $(F=2.35, p<.1)$, whereas it shows no impact for the other items. Therefore, the hypothesis H4 was not supported by overall green behaviors, whereas it was partially supported by purchasing pro-environmental products.

The influence of subjective social class on practicing green behaviors was analyzed. The results indicate that subjective social class significantly influences on the overall green practice $(F=5.38, p<.01)$. Therefore, the hypothesis H5 was supported (see Table 2). And post-hoc analysis reveals that subjective high class (vs. subjective middle or low class) people are more likely to practice green behaviors . More specifically, subjective social class has a significant influence on purchasing pro-e nvironmental products $(F=4.75, p<.01)$, recycling $(F=5.01, p<.01)$, and initiating green practices $(F=7.10, p<.01)$. 
〈Table 2〉 Socio-demographics and Practices of Green Behaviors

\begin{tabular}{|c|c|c|c|c|c|c|c|c|c|c|}
\hline Variables & statistics & \multicolumn{9}{|c|}{ classification } \\
\hline \multirow[t]{3}{*}{ Age } & & $20 \mathrm{~s}$ & & \multicolumn{2}{|r|}{$30 \mathrm{~s}$} & \multicolumn{2}{|c|}{$40 \mathrm{~s}$} & $50 \mathrm{~s}$ & \multicolumn{2}{|r|}{$\geq 60$ s } \\
\hline & $\mathrm{N}$ & 281 & & \multicolumn{2}{|r|}{328} & \multicolumn{2}{|c|}{342} & 367 & \multicolumn{2}{|r|}{282} \\
\hline & Mean(SD) & 2.78 & & \multicolumn{2}{|c|}{$2.85(.69)$} & \multicolumn{2}{|c|}{$3.08(.70)$} & $3.12(.76)$ & \multicolumn{2}{|c|}{$3.20(.81)$} \\
\hline \multirow[t]{3}{*}{ Gender*** } & & \multicolumn{4}{|c|}{ Male } & \multicolumn{2}{|c|}{ Female } & & & \\
\hline & $\mathrm{N}$ & \multicolumn{4}{|c|}{702} & \multicolumn{2}{|c|}{798} & & & \\
\hline & Mean (SD) & \multicolumn{4}{|c|}{$2.94(.76)$} & \multicolumn{2}{|c|}{$3.06(.76)$} & & & \\
\hline \multirow[t]{3}{*}{ Education } & & \multicolumn{3}{|c|}{$\begin{array}{l}\text { Middle School or } \\
\text { below }\end{array}$} & \multicolumn{2}{|c|}{ High School } & \multicolumn{2}{|c|}{ Bachelor's degree } & \multicolumn{2}{|c|}{$\begin{array}{c}\text { Graduate school or } \\
\text { above }\end{array}$} \\
\hline & $\mathrm{N}$ & \multicolumn{3}{|c|}{128} & \multicolumn{2}{|c|}{488} & \multicolumn{2}{|c|}{777} & \multicolumn{2}{|c|}{107} \\
\hline & Mean(SD) & \multicolumn{2}{|c|}{$3.05(.86)$} & \multicolumn{3}{|c|}{$3.03(.76)$} & \multicolumn{2}{|c|}{$2.97(.74)$} & 3.12 & $(.74)$ \\
\hline Monthly Income & & Under 1 & .500 & & $500 \sim 2,499$ & \begin{tabular}{l|l}
2,500 \\
\end{tabular} & $-4,499$ & $4,500 \sim 6,499$ & & ove 6,500 \\
\hline & $\mathrm{N}$ & 306 & & & 302 & 47 & & 283 & & 131 \\
\hline & Mean(SD) & $2.98(.7$ & & & $2.95(.74)$ & 2.99 & .77) & $3.10(.76)$ & & $.04(.67)$ \\
\hline Subjective social & & high & & & per middle & Lower & middle & Upper low & & wer low \\
\hline & $\mathrm{N}$ & 41 & & & 295 & 64 & & 332 & & 190 \\
\hline & Mean(SD) & 3.31 & & & $3.07(.76)$ & 3.04 & $(.71)$ & $2.89(.78)$ & & $90(.85)$ \\
\hline Marital status*** & & & Inmarr & & & Mar & ried & & & \\
\hline & $\mathrm{N}$ & & 187 & & & 13 & 13 & & & \\
\hline & Mean(SD) & & $.73(.7$ & & & 3.04 & (.75) & & & \\
\hline Occupation**** & & 1 & 2 & & 3 & 4 & 5 & 6 & 7 & 8 \\
\hline & $\mathrm{N}$ & 303 & 41 & & 174 & 127 & 191 & 90 & 114 & 85 \\
\hline & Mean(SD) & $3.09(.71)$ & 2.96( & & $2.90(.78)$ & $2.88(.75)$ & $3.22(.71)$ & $2.85(.76)$ & $2.98(.72)$ & $3.05(.86)$ \\
\hline
\end{tabular}

***: $p<.01$, N: subjects, SD: standard deviation, income: thousand Won, occupation: $1=$ professionals/managers, $2=$ clerks/technicians, $3=$ sales/services, $4=$ elementary/non-skilled/production/transport, $5=$ homemaker, $6=$ students, $7=$ self-employed, $8=$ others/unemployed

The influence of occupation on practicing green behaviors was analyzed. The results indicate that occupation significantly influences on overall green practice $(F=4.57, p<.01)$ (see Table 2). Therefore, the hypothesis H6 was supported. More specifically, occupation has a significant influence on purchasing proenvironmental products $(F=2.44, p<.05)$, en- ergy saving $(F=2.94, p<.01)$, recycling $(F=$ $5.20, p<.001)$, and initiating green practices $(F=2.25, p<.05)$.

The influence of marital status on practicing green behaviors was analyzed. The results indicate that marital status significantly influences on overall green practice $(F=28.28, p<$ .001) (see Table 2). Therefore, the hypothesis 
H7 was supported. More specifically, marital status has a significant influence on purchasing pro-environmental products $(F=10.12, p<.01)$, energy saving $(F=12.14, p<.01)$, recycling $(F=34.46, p<.001)$, and initiating green practices $(F=14.79, p<.001)$.

\section{Green-Consumer Segmentation and Profiling}

Recently, Chen et al. (2014) simultaneously reported demographic influences and cluster segmentation. In line with the Chen et al.'s report (2014) and recommendations from Allenby et al. (2003), this paper showed not only the influence of socio-demographics on practices for green behaviors, but also the profile of green consumers based on clustering methodology.

Using k-means cluster analysis, based on prac- tices for green-behavior variables, a three-cluster solution was decided on for extraction. In order to demonstrate that the extracted clusters were effective, the difference of green-behavior practices in terms of the three clusters was analyzed. The results show that classified clusters have a significant difference on practices for green behaviors (see Table 3). More specifically, classified clusters significantly alter overall green practices $(F=1118.50, p<.001)$, purchasing pro-environmental products $(F=232.91$, $p<.001)$, energy saving $(F=522.02, p<.001)$, recycling $(F=1192.09, p<.001)$, and initiating green practices $(F=847.59, p<.001)$.

Next, this paper described segments and profiles concerning three clusters of green practices. The proportion of cluster 1 out of the total sample size was $33.1 \%$, the proportion of cluster 2 was $20.8 \%$, and the proportion of cluster 3 was $46.1 \%$. Considering each item's score for practices of green behaviors, each cluster's name

〈Table 3〉 Green Consumer Clusters and Practices of Green Behaviors

\begin{tabular}{|c|c|c|c|c|c|c|c|}
\hline $\begin{array}{l}\text { clusters } \\
\text { name }\end{array}$ & subjects & proportion & $\begin{array}{l}\text { overall green } \\
\text { practice }\end{array}$ & $\begin{array}{c}\text { purchasing } \\
\text { pro-environme } \\
\text { ntal products }\end{array}$ & $\begin{array}{l}\text { energy } \\
\text { saving }\end{array}$ & recycling & $\begin{array}{l}\text { initiating green } \\
\text { practice }\end{array}$ \\
\hline $\begin{array}{c}\text { Active green } \\
\text { consumer }\end{array}$ & 497 & $33.1 \%$ & $\begin{array}{l}3.79 \\
(.43) \\
\end{array}$ & $\begin{array}{l}3.31 \\
(.79) \\
\end{array}$ & $\begin{array}{l}3.91 \\
(.69) \\
\end{array}$ & $\begin{array}{l}4.26 \\
(.58) \\
\end{array}$ & $\begin{array}{l}3.68 \\
(.68) \\
\end{array}$ \\
\hline $\begin{array}{l}\text { Utilitarian } \\
\text { green } \\
\text { consumer }\end{array}$ & 312 & $20.8 \%$ & $\begin{array}{l}2.99 \\
(.37)\end{array}$ & $\begin{array}{l}2.65 \\
(.83)\end{array}$ & $\begin{array}{l}3.48 \\
(.74)\end{array}$ & $\begin{array}{l}4.12 \\
(.61)\end{array}$ & $\begin{array}{l}1.71 \\
(.56)\end{array}$ \\
\hline $\begin{array}{l}\text { Inactivated } \\
\text { green } \\
\text { consumer }\end{array}$ & 691 & $46.1 \%$ & $\begin{array}{l}2.45 \\
(.55)\end{array}$ & $\begin{array}{l}2.32 \\
(.75)\end{array}$ & $\begin{array}{l}2.60 \\
(.70)\end{array}$ & $\begin{array}{l}2.60 \\
(.68)\end{array}$ & $\begin{array}{l}2.22 \\
(.81)\end{array}$ \\
\hline
\end{tabular}

Notes: Means are listed with standard deviations in parentheses. 
was assigned as 'active green consumer', (cluster 1) 'utilitarian green consumer,' (cluster 2) and 'inactivated green consumer' (cluster 3).

Green behavioral characteristics of an active green consumer' are that they demonstrate active practices for all green behavior components such as purchasing pro-environmental products, energy saving, recycling, and initiating green behaviors compared to inactivated green consumer,' whereas characteristics of a 'utilitarian green consumer' show relatively active practices in utilitarian domains such as energy saving and recycling, but passive practices in purchasing pro-environmental products and the

〈Table 4〉 Green Consumer Segments and Profiles

\begin{tabular}{|c|c|c|c|c|c|c|c|}
\hline \multirow[b]{2}{*}{$\begin{array}{l}\text { profiles } \\
\text { criteria }\end{array}$} & \multirow[b]{2}{*}{ details } & \multicolumn{3}{|c|}{ Between clusters (\%) } & \multicolumn{3}{|c|}{ Within cluster (\%) } \\
\hline & & $\begin{array}{c}\text { active } \\
\text { green } \\
\text { consumer }\end{array}$ & $\begin{array}{c}\text { utilitarian } \\
\text { green } \\
\text { consumer }\end{array}$ & $\begin{array}{l}\text { inactivated } \\
\text { green } \\
\text { consumer }\end{array}$ & $\begin{array}{c}\text { active } \\
\text { green } \\
\text { consumer }\end{array}$ & $\begin{array}{c}\text { utilitarian } \\
\text { green } \\
\text { consumer }\end{array}$ & $\begin{array}{c}\text { inactivated } \\
\text { green } \\
\text { consumer }\end{array}$ \\
\hline & Cluster size & 33.1 & 20.8 & 46.1 & 100.0 & 100.0 & 100.0 \\
\hline \multirow[t]{5}{*}{ Age $e^{* * *}$} & $20 \mathrm{~s}$ & 21.4 & 24.2 & 54.4 & 12.1 & 21.8 & 22.1 \\
\hline & $30 \mathrm{~s}$ & 25.3 & 21.3 & 53.4 & 16.7 & 22.4 & 25.3 \\
\hline & $40 \mathrm{~s}$ & 38.9 & 22.2 & 38.9 & 26.8 & 24.4 & 19.2 \\
\hline & $50 \mathrm{~s}$ & 37.8 & 20.2 & 41.9 & 20.3 & 17.3 & 16.2 \\
\hline & 60 s or above & 42.6 & 15.6 & 41.8 & 24.1 & 14.1 & 17.1 \\
\hline \multirow[t]{2}{*}{ Gender**** } & Male & 30.3 & 17.5 & 52.1 & 42.9 & 39.4 & 53.0 \\
\hline & Female & 35.6 & 23.7 & 40.7 & 57.1 & 60.6 & 47.0 \\
\hline \multirow[t]{8}{*}{ Occupation**** } & 1 & 40.3 & 17.5 & 42.2 & 24.5 & 17.0 & 18.5 \\
\hline & 2 & 32.0 & 21.6 & 46.4 & 26.8 & 28.8 & 27.9 \\
\hline & 3 & 29.3 & 16.7 & 54.0 & 10.3 & 9.3 & 13.6 \\
\hline & 4 & 27.6 & 16.5 & 55.9 & 7.0 & 6.7 & 10.3 \\
\hline & 5 & 39.8 & 27.2 & 33.0 & 15.3 & 16.7 & 9.1 \\
\hline & 6 & 24.4 & 24.4 & 51.1 & 4.4 & 7.1 & 6.7 \\
\hline & 7 & 23.7 & 29.8 & 46.5 & 5.4 & 10.9 & 7.7 \\
\hline & 8 & 36.5 & 12.9 & 50.6 & 6.2 & 3.5 & 6.2 \\
\hline \multirow{2}{*}{$\begin{array}{c}\text { Marital } \\
\text { Status }^{* * *}\end{array}$} & Unmarried & 19.8 & 19.8 & 60.4 & 7.4 & 11.9 & 16.4 \\
\hline & Married & 35.0 & 20.9 & 44.0 & 92.6 & 88.1 & 83.6 \\
\hline \multirow{5}{*}{$\begin{array}{c}\text { Subjective } \\
\text { Social Class** }\end{array}$} & High & 39.0 & 9.8 & 51.2 & 3.2 & 1.3 & 3.0 \\
\hline & Upper middle & 35.9 & 20.7 & 43.4 & 21.3 & 19.6 & 18.5 \\
\hline & Lower middle & 35.5 & 22.4 & 42.1 & 45.9 & 46.2 & 39.1 \\
\hline & Upper low & 28.6 & 21.4 & 50.0 & 19.1 & 22.8 & 24.0 \\
\hline & Lower low & 27.4 & 16.8 & 55.8 & 10.5 & 10.3 & 15.3 \\
\hline
\end{tabular}

Notes: $\chi^{2}$-tests, ${ }^{* * *}: \mathrm{p}<.01,{ }^{* *}: \mathrm{p}<.05$, occupation: $1=$ professionals/managers, $2=$ clerks/technicians, $3=$ sales/services, $4=$ elementary/non-skilled/production/transport, $5=$ homemaker, $6=$ students, $7=$ Self-employed, $8=$ others/unemployed 
lowest intensities in initiating green behaviors among three segments. The inactivated green consumer' does not have lower intensities in initiating green behaviors compared to the 'utilitarian green consumer'.

This paper analyzed socio-demographic variables in terms of the three clusters and analyzed profiling for each segment (see Table 4). $x^{2}$ - tests showed that the profiles of 3 clusters are significantly influenced by age $\left(\chi^{2}(8)=\right.$ 50.19, $p<.001)$, gender $\left(\chi^{2}(2)=20.47, p<\right.$ $.001)$, occupation $\left(\chi^{2}(14)=44.37, p<.001\right)$, subjective social class $\left(\chi^{2}(8)=21.43, p<.05\right)$, and marital status $\left(\chi^{2}(2)=21.15, p<.001\right)$.

Compared to each segment's categorical potential, the summarized profile variables for the 'active green consumer' segment (33.1\%) are: relatively older (aged 40 or above), female, occupations belonging to professionals/manager, homemaker, and clerks/technicians sectors, and self-reported subjective upper social class.

Summarized profile variables for the "utilitarian green consumer' segment (20.8\%) are: relatively younger (in their 20s), and occupations belonging to self-managed and homemaker.

Summarized profile variables for the inactivated green consumer' segment (46.1\%) are: relatively younger (aged 30 and below), male, occupations belonging to production/transportation/ sales/service/elementary/non-skilled, and students, unmarried status, and self-reported subjective low social status.

\section{General Discussion and Conclusion}

\subsection{General Findings Summary}

As a results of hypothesis testing, a significant relationship was found between socio-demographics such as age (H1), gender (H2), occupation (H5), subjective social class (H6) and marital status (H7) and green behaviors, whereas non-significant or partially significant relationships were seen between socio-demographics such as education and income and green behaviors.

General findings are summarized as: 1) older people used green practices more strongly than younger people, 2) female subjects demonstrated better energy-saving and recycling practices compared to males, 3) marital status also significantly influenced green-related behaviors, 4) subjective social class had a significant influence on green-related behaviors, 5) education level and income, however, weakly influenced or showed no impact on green-related behaviors, and 6) a green consumer was classified as an 'active green consumer,' 'utilitarian green consumer,' or 'inactivated green consumer.' Implications for findings from clustering green segments were initially mentioned, and then general implications were developed from sociodemographics. 


\subsection{Contributions and Implications}

Most socio-demographic variables may still have a significant influence on practices of green behaviors in the Republic of Korea. The results of this study show that age, gender, marital status, occupation, and subjective social class are major segmenting criteria, whereas education and income are not. The results differ from other studies in Korea. For example, Shin and Shin (2012) found that green segments have significantly different characteristics such as marital status, age, education, occupation, housing type, income, whereas not such as gender, number of family members. Kim (2014) found that age alone was differentiated by green segments. Jung and Cho (2014) showed that gender and age significantly influenced on green products purchasing behavior and green consumption life, whereas education level and family income were not.

Socio-demographic characteristics of Korean green consumer have different features compared to other country's survey results. For example, the results of do Paço and Raposo (2010) show that age, education, income, and occupation are major segmenting criteria, whereas gender is not. The results of Sütterlin et al. (2011) show that age, gender, educational level and income class are significantly differentiated segment criteria.

It would be likely that, having people with ample opportunities to learn green-related in- formation in line with the wide spread of information technology (e.g., smart-phones), the media has made education and income levels relatively less influential factors in the Republic of Korea. That is, green-related information was sufficiently provided to most people through various forms of media.

The green-consumer segments and profiling characteristics resulting from this work showed somewhat different from other researches. For example, do Paço and Raposo (2010) classified green consumers into three segments: "the uncommitted,' 'the green activists,' and 'the undefined, and listed each proportion as 36\%, 35\%, and $29 \%$, respectively. Sütterlin et al. (2011, p. 8144) classified energy savers as comprising six clusters, that is 'the idealistic' (15.6\%), 'the selfless inconsequent' (26.4\%), 'the thrifty' (14\%), 'the materialistic' $(25.1 \%)$, 'the convenienceoriented indifferent' $(5.3 \%)$, and 'the problemaware well-being-oriented energy consumer' (13.6\%). Shin and Shin (2012) classified green consumers as four clusters, based on self-concept and green consumerism, 'unclear /skeptical' group (12.1\%), independent/green consumerism' group (21.1\%), 'dependent/skeptical' group (43.6\%), and 'meta-personal/green consumerism' group (23.2\%). But this study classified green consumers into three clusters such as 'active green consumer'(33.1\%), 'utilitarian green consumer' (20.8\%), or 'inactivated green consumer' $(46.1 \%)$.

On average, the profile of an active green consumer' group shows an individual who is 
relatively older, and/or female. Subjective upper social class status and occupations such as professionals/manager, homemakers and clerks/ technicians are supplementary aspects of these profiles. The profile of an active green consumer' group has somewhat different features when compared to other countries' consumers or residents, especially in terms of income and education. For example, Abeliotis et al. (2010), studying Greek consumers' participation in the 3Rs (reduce-reuse-recycle), reported that green consumers commonly shared features such as being middle aged women with low incomes (p. 159). do Paço and Raposo (2010), studying Portuguese consumers' environmental variables, showed that green activists had features of higher education, more qualified jobs and higher incomes (p. 435). Nasir and Karakaya (2014), surveying one of European city, reported that organic foods were mostly favored by females, younger people, well-educated persons, and lowor middle income earners. Pedrini and Ferri (2014), in surveying Italian residents, reported that older, highly educated, and higher income earners had a higher propensity for buying responsible products (p. 133).

The distinctive characteristic-embedded segment for green-consumer profiling in the Republic of Korea is the 'utilitarian green consumer' group. A 'utilitarian green consumer' exists between the clusters of 'active green consumer' and 'inactivated green consumers'. The 'utilitarian green consumer' group, however, is not simply positioned between the 'active green consumer' and 'inactivated green consumer' groups. The group practices energy saving and recycling behaviors at the similar levels as green consumers, whereas they omit passive practices in purchasing pro-environmental products and show the lowest intensities for initiating green behaviors among the three segments. This probably means that the group behaves pragmatically. It is, therefore, an important policy initiative for the group to engage in social interactions and share green value with ideal green consumers and to endow group incentives (e.g., not for the individual, but for the family) in order to improve and motivate green behaviors.

While the 'utilitarian green consumer' group has similar features to segments labeled by do Paço and Raposo (2010) as 'the undefined' and by Sütterlin et al. (2011) as 'the selfless inconsequent' or 'the thrifty', from the perspective of recycling and energy-saving behaviors, the group has dissimilar features such as low practices for initiating green behaviors. It can be drawn some implications for policy making from socio-demographic analyses and segmentation of green consumers. Firstly, it is necessary to improve practices of green behaviors to target younger people. Prior research has shown that younger people have more knowledge of environmental issues. For example, Cheah et al. (2011) found that younger people are socially responsible investors (SRIs), and hold stronger beliefs that the environmental performance of 
a corporation is as important as its financial performance. Diamantopoulos et al. (2003), however, found that age was negatively correlated with environmental knowledge and attitudes, whereas age was positively (though not with purchasing behavior) correlated with recycling behaviors. This means that age is likely to be a major driving cause of the attitude-behavior gap. Therefore, learning how to transform knowledge in young people into actual green practices is an important policy issue.

Secondly, it is also necessary to practice green behaviors in the workplace. Some participants with different occupations showed fewer green behaviors than the average green-consumer market potential. Greening the workplace (e.g., with green buildings), in which production-related workers and non-skilled workers are employed, is one of the alternatives to better engaging in green behaviors. Green campuses are another way to improve student practices for green behaviors.

Thirdly, motivating females to be greener is likely to have an effect as an efficient way of obtaining green goals. Self-transcendent values were more highly possessed by females than by males (Pinto et al. 2014). And also females, compared to males, as socially responsible investors (SRIs), valued social responsibility over financial returns and were more likely to be SRIs (Junkus and Berry 2010; Nilsson 2008). Housewives tended to practice green behaviors actively and belonged to the 'utilitarian green' segment with a relatively high occurrence. Therefore, facilitating social interactions among housewives (e.g., sharing green information) would diffuse green behaviors more swiftly.

Fourthly, it is an important policy initiative to voluntarily promote green behaviors in 'utilitarian green consumer' segment. Considered cluster's characteristics, it is essential to provide accurate information with middle-aged consumers and promote convenient choice. For example, older and middle-aged respondents, compared to younger ones, were highly dissatisfied and skeptical with green labels because of their inaccuracy (D'Souza et al. 2007). And convenient choice of green-related products can be helpful to implement green related activities (Hjelmar 2011).

Finally, it seems plausible that the "inactivated green consumer' group has the potential willpower to initiate green practices compared to the 'utilitarian green consumer' group. This means that the 'inactivated green consumer' segment has a need to initiate green behaviors. Therefore, in this segment, marketers or policy-makers should encourage turning the group's willpower into practice. Extrinsic incentives, coupled with interdependent mind-sets or self-transcendent values, are needed to improve green behaviors. For example, energy-saving behaviors derived from both financial and energy conscious motives (Sütterlin et al. 2011) and encouraging social identity can help males become better green consumers (Pinto et al. 2014). It is, therefore, 
an important policy initiative to activate the mind-set for green behaviors and incentive- linked activities in this group. Alongside with implications for consumers, since green marketing is now considered a major irrevocable business trend (Kassaye 2001), it is necessary for marketers to understand consumer behavior related to green products and services. Organizations might gain a competitive advantage through environmental attributes (Chen and Chai 2010) and might achieve positive financial performances (Molina-Azorín et al. 2009) through a commitment to green management.

Understanding green-consumer profiling and behaviors is very important for marketers as well as policy makers. Besides the ecological concerns for impacts on brand preference (Kinnear and Taylor 1973), the impact of socio-demographic variables on preference for green products, services, and, therefore, organizations can develop targeting and positioning strategies for green products and services based on these variables (D’Souza, Taghian, and Khosla 2007). When considering strategies or (public) policies based on socio-demographics, it is important for strategists or policy makers to clearly decide their strategic or policy implementation levels (Schlegelmilch et al. 1996).

\subsection{Limitations and further suggestions}

This study has some limitations. Even though the data used in this study was nationwide sur- vey data, the derived factors and conclusions are generalized because the data were drawn from a single data source.

Investigating socio-demographics coupled with psycho-graphics is needed. For example, Taylor and Todd (1995) investigated antecedents of household garbage-reduction behaviors and found that perceived behavioral control, which was affected by self-efficacy, influenced garbagereduction behaviors. Socio-demographics were likely to interact with other variables. For example, Shrum et al. (1995) found that greenpurchasing behavioral intentions (e.g., making a special effort to buy green or switching brands to buy green) was influenced by consumer attitudes and gender.

It is necessary to consider contextual variables. Of great import, demographic variables $\mathrm{dy}^{-}$ namically influence environmentally-friendly behavioral intentions as well as having crosssectional impacts. For example, Mehmetoglu's study on Norwegian (2010) found that each socio-demographic variable differentially influences under specific circumstances. For example, the environmentally-friendly behavioral intentions of Norwegian respondents were influenced by age and education when they stayed at home, whereas influenced by income and gender when they visited a destination.

Green-consumer behaviors might vary dependent upon social interactions. For example, an individual's greening is likely to be influenced by social interactions with a spouse or 
family member (Macey and Brown 1983; Neuman 1986). Chan (1999) found that heavy green consumers (vs. light green consumers) were susceptible to other consumers or other influencers as well as environmental concerns.

This study has some room for further suggestions. First, green-consumer behaviors may vary depending upon behavioral domains or objects. For example, Brookers (1976) found that the influence of age on purchasing green products depended on the products themselves (e.g., "lead free gasoline purchase' was influenced by age but not in 'phosphate-free detergent purchase'). Diamantopoulos et al. (2003) found that educational levels significantly influenced recycling behaviors but not purchasing behaviors, and also found that age was positively correlated with recycling but not purchasing behaviors. Therefore it is useful that green behaviors divide into green-related domains or objects and compare amongst these domains or objects.

Second, macro level analyses are needed. Economic development stages or cultural differences might influence green-related issues, such as environmental knowledge, attitude towards green life, pro-environmental behaviors, or purchasing environmentally-friendly products (Laroche et al. 2002).

\subsection{Concluding Remarks}

In the $21^{\text {st }}$ century, green consumer behavior, playing one of the core roles of sustainability, is still an important issue to green-related stakeholders. Socio-demographic variables have endured as profoundly researched elements in green consumer behavior because of usefulness in segmentation and profiling green consumer. Therefore what academic researchers need is continued interest to socio-demographics as well as psycho-graphics.

〈Received August 18. 2014〉 〈1st Revised December 26. 2014〉 〈2nd Revised February 26. 2015〉 〈Accepted March 11. 2015〉

\section{References}

Abeliotis, Konstadinos, Christina Koniari, and Eleni Sardianou (2010), "The Profile of the Green Consumer in Greece," International Journal of Consumer Studies, 34 (2), 153-160.

Akehurst, Gary, Carolina Afonso, and Helena Martins Gonçalves (2012), “Re-examining Green Purchase Behaviour and the Green Consumer Profile: New Evidences," $\mathrm{Ma}^{-}$ nagement Decision, 50 (5), 972-988.

Allenby, Greg, Geraldine Fennell, Albert Bemmaor, Vijay Bhargava, Francois Christen, Jackie Dawley, Peter Dickson, Yancy Edwards, Mark Garratt, Jim Ginter, Alan Sawyer, Rick Staelin, and Sha Yang (2002), "Market Segmentation Research: Beyond Within 
and Across Group Differences," Marketing Letters, 13 (3), 233-243.

Balderjahn, Igno (1988), "Personality Variables and Environmental Attitudes as Predictors of Ecologically Responsible Consumption Patterns," Journal of Business Research, 17 (1), 51-56.

Brooker, George (1976), "The Self-Actualizing Socially Conscious Consumer," Journal of Consumer Research, 3 (2), 107-112.

Chan, Ricky Y. K. (1999), "Market Segmentation of Green Consumers in Hong Kong," Journal of International Consumer Marketing, 12 (2), 7-23.

Chan, Ricky Y. K. and Lorett B. Y. Lau (2002), "Explaining Green Purchasing Behavior: A Cross-cultural Study on American and Chinese Consumers," Journal of International Consumer Marketing, 14 (2/3), 9-40.

Cheah, Eng-Tuck, Dima Jamali, Johnnie E. V. Johnson, and Ming-Chien Sung (2011), "Drivers of Corporate Social Responsibility Attitudes: The Demography of Socially Responsible Investors," British Journal of Management, 22 (2), 305-323.

Chen, Jue, Antonio Lobo, and Natalia Rajendran (2014), "Drivers of Organic Food Purchase Intentions in Mainland China - Evaluating Potential Customers' Attitudes, Demographics and Segmentation," International Journal of Consumer Studies, 38 (4), 346-356.

Chen, T. and L. Chai (2010), "Attitude towards the Environment and Green Products: Con- sumers' Perspective, Management Science and Engineering, 4 (2), 27-39.

Cicia, Gianni, Teresa Del Giudice, and Riccardo Scarpa (2002), “Consumers' Perception of Quality in Organic Food: A Random Utility Model under Preference Heterogeneity and Choice Correlation from Rank-orderings," British Food Journal, 104(3/4/5), 200-213.

Claudy, Marius C., Mark Peterson, and Aidan O'Driscoll (2013), "Understanding the AttitudeBehavior Gap for Renewable Energy Systems Using Behavioral Reasoning Theory," Journal of Macromarketing, 33 (4), 273-287. Corradi, Nicola, Konstantinos Priftis, Giulio Jacucci, and Luciano Gamberini (2013), "Oops, I Forgot the Light on! The Cognitive $\mathrm{Me}^{-}$ chanisms Supporting the Execution of Energy Saving Behaviors," Journal of Economic Psychology, 34, 88-96.

Culiberg, Barbara (2014), “Towards an Understanding of Consumer Recycling from an Ethical Perspective," International Journal of Consumer Studies, 38 (1), 90-97.

D’Souza, Clare, Mehdi Taghian, and Rajiv Khosla (2007), "Examination of Environmental Beliefs and its Impact on the Influence of Price, Quality and Demographic Characteristics with Respect to Green Purchase Intention," Journal of Targeting, Measurement and Analysis for Marketing, 15 (2), 69-78.

D’Souza, Clare, Mehdi Taghian, Peter Lamb, and Roman Peretiatko (2007), "Green De- 
cisions: Demographics and Consumer Understanding of Environmental Labels," International Journal of Consumer Studies, 31 (4), 371-376.

Davies, Anne, Albert J. Titterington, and Clive Cochrane (1995), "Who Buys Organic Food? A Profile of the Purchasers of Organic Food in Northern Ireland," British Food Journal, 97 (10), 17-23.

Davies, Janette, Gordon R. Foxall and John Pallister (2002), "Beyond the IntentionBehaviour Mythology: An Integrated Model of Recycling," Marketing Theory, 2 (1), 29-113.

Diamantopoulos, Adamantios, Bodo B. Schlegelmilch, Rudolf R. Sinkovics, and Greg M. Bohlen (2003), "Can Socio-demographics Still Play a Role in Profiling Green Consumers? A Review of the Evidence and an Empirical Investigation," Journal of Business Research, 56 (6), 465-480.

do Paço, Arminda M. Finisterra and Mário Lino Barata Raposo (2010), "Green Consumer Market Segmentation: Empirical Findings from Portugal," International Journal of Consumer Studies, 34 (4), 429-436.

do Paço, Arminda M. Finisterra, Mário Lino Barata Raposo, and Walter Lead Filho (2009), "Identifying the Green Consumer: A Segmentation Study," Journal of Targeting, Measurement \& Analysis for Marketing, 17 (1), 17-25.

do Paço, Arminda and Lilia Varejâo (2010),
"Factors Affecting Energy Saving Behaviour: A Prospective Research," Journal of Environmental Planning \& Management, 53 (8), 963-976.

Gleim, Mark R. Jeffery S. Smith, Demetra Andrews, and J. Joseph Cronin Jr. (2013), "Against the Green: A Multi-method Examination of the Barriers to Green Consumption," Journal of Retailing, 89 (1), 44-61.

Granzin, Kent L. and Janeen E. Olsen (1991), "Characterizing Participants in Activities Protecting the Environment: A Focus on Donating, Recycling and Conservation $\mathrm{Be}^{-}$ haviors, Journal of Public Policy \& Marketing, 10 (2), 1-27.

Henion, Karl E. (1972), "The Effect of Ecologically Relevant Information on Detergent Sales," Journal of Marketing Research, 9 (2), 10-14.

Hjelmar, Ulf (2011), "Consumers' Purchase of Organic Food Products. A Matter of Convenience and Reflexive Practices," Appetite, 56 (2), 336-344.

Hori, Shiro, Kayoko Kondo, Daisuke Nogata, and Han Ben (2013), “The Determinants of Household Energy-saving Behavior: Survey and Comparison in Five Major Asian Cities," Energy Policy, 52, 354-362.

Hughner, Renée Shaw, Pierre McDonagh, Andrea Prothero, Clifford J. Shultz II and Julie Stanton (2007), "Who are Organic Food Consumers? A Compilation and Review of Why People Purchase Organic Food," Journal 
of Consumer Behaviour, 6 (2/3), 94-110.

Hwang, Eunae and Jiyeon Son (2013), 2013 Consumption Life Indicators in Korea, Korea Consumer Agency.

Joung, S. H., S. W. Park, and Y. J. Ko (2014), "Willingness to Pay for Eco-friendly Products: Case of Cosmetics," Asia Marketing Journal, 15 (4), 33-49.

Jung, J.-W. and S.-Y. Cho (2014), "The Effect of Cognition Degree of Green Life on Green Consumer Behavior," Journal of Environmental Science International, 23 (8), 1455-1462.

Junkus, Joan C. and Thomas C. Berry (2010), "The Demographic Profile of Socially Responsible Investors," Managerial Finance, 36 (6), 474-481.

Iyer, Easwar S. and Rajiv K. Kashyap (2007), "Consumer Recycling: Role of Incentives, Information, and Social Class," Journal of Consumer Behaviour, 6 (1), 32-47.

Kalafatis, Stavros P., Michael Pollard, Robert East, and Markos H. Tsogas (1999), "Green Marketing and Ajzen's Theory of Planned Behaviour: A Cross-market Examination," Journal of Consumer Marketing, 16 (5), 441-460.

Kassarjian, Harold H. (1971), "Incorporating Ecology into Marketing Strategy: The Case of Air Pollution," Journal of Marketing, 35 (7), 61-65.

Kassaye, W. Wossen (2001), "Green dilemma," Marketing Intelligence \& Planning, 19 (6),
444-455.

Kim, H. (2014), "Segmentation of Green Consumers and Willingness to Purchase Green Products of University Students," Journal of Korean Society for Environmental Education, 27 (1), 51-68.

Kinnear, Thomas C. and James R. Taylor (1973), "The Effect of Ecological Concern on Brand Perception," Journal of Marketing Research, 10 (2), 191-197.

Kinnear, Thomas C., James R. Taylor, and Sadrudin A. Ahmed (1974), "Ecologically Concerned Consumers: Who are They?," Journal of Marketing, 38 (2), 20-24.

Korea Consumer Agency (1993), http://www. kca.go.kr $/ \mathrm{brd} / \mathrm{m} \_46 /$ view.do?seq $=961$

Laroche, Michel, Jasmin Bergeron, and Guido Barbaro-Forleo (2001), “Targeting Consumers Who are Willing to Pay More for Environmentally Friendly Products," Journal of Consumer Marketing, 18 (6), 503-520.

Laroche, Michel, Marc-Alexandre Tomiuk, Jasmin Bergeron and Guido Barbaro-Forleo (2002), "Cultural Differences in Environmental Knowledge, Attitudes, and Behaviors of Canadian Consumers," Canadian Journal of Administrative Sciences, 19 (3), 267-283.

Leonidou, Constantinos N. and Leonidas C. Leonidou (2011), "Research into Environmental Marketing/Management: A Bibliographic Analysis," European Journal of Marketing, 45 (1/2), 68-103.

Macey, Susan M. and Marilyn A. Brown (1983), 
"Residential Energy Conservation through Attitudes and Beliefs," Environment and Behavior, 15 (2), 123-141.

Mainieri, Tina, Elaine G. Barnett, Trisha R. Valdero, John B. Unipan, and Stuart Oskamp (1997), "Green Buying: The Influence of Environmental Concern on Consumer Behaviour," Journal of Social Psychology, 137 (2), 189-204.

Mehmetoglu, Mehmet (2010), "Factors Influencing the Willingness to Behave Environmentally Friendly at Home and Holiday Settings," Scandinavian Journal of Hospitality \& Tourism, 10 (4), 430-447.

Molina-Azorín, José F., Enrique Claver-Cortés, Maria D. López-Gamero and Juan J. Tarí (2009), "Green Management and Financial Performance: A Literature Review," Management Decision, 47 (7), 1080-1100.

Mostafa, Mohamed M. (2007), "A Hierarchical Analysis of the Green Consciousness of the Egyptian Consumers," Psychology \& Marketing, 24 (5), 445-473.

Nasir, V. Ashlihan and Fahri Karakaya (2014), "Consumer Segments in Organic Foods Market," Journal of Consumer Marketing, 31 (4), 263-277.

Neuman, Keith (1986), "Personal Values and Commitment to Energy Conservation," Environment and Behavior, 18 (1), 53-74.

Nilsson, Jonas (2008), "Investment with a Conscience: Examining the Impact of Prosocial Attitudes and Perceived Financial
Performance on Socially Investment $\mathrm{Be}^{-}$ havior," Journal of Business Ethics, 83 (2), 307-325.

Peattie, Ken and Martin Charter (2003), Green marketing, in Baker, M. (Ed.), The Marketing Book, 5th ed., Butterworth-Heinemann, Oxford, 726-756.

Pedrini, Matteo and Laura Maria Ferri (2014), "Socio-demographical antecedents of $\mathrm{Re}^{-}$ sponsible Consumerism Propensity," International Journal of Consumer Studies, 38 (2), 127-138.

Pinto, Diego Costa, Márcia M. Herter, Patricia Rossi, and Adilson Borges (2014), "Going Green for Self or for Others? Gender and Identity Salience Effects on Sustainable Consumption," International Journal of Consumer Studies, 38(5), 540-549.

Polonsky, Michael, William Kilbourne, and Andrea Vocino (2014), "Relationship between the Dominant Social Paradigm, Materialism and Environmental Behaviours in Four Asian Economies," European Journal of Marketing, $48(3 / 4), 522-551$.

Prothero, Andrea (1996), "Environmental Decisionmaking: Research Issues in the Cosmetics and Toiletries Industry," Marketing Intelligence \& Planning, 14 (2), 19-25.

Roberts, James A. (1996), “Green Consumers in the 1990s: Profile and Implications for Advertising," Journal of Business Research, 36 (3), 217-232.

Samdahl, Diane M. and Robert Robertson (1989), 
"Social Determinants of Environmental Concern: Specification and Test of the Model," Environment and Behavior, 21 (1), 57-81.

Schlegelmilch, Bodo B., Greg M. Bohlen, and Adamantios Diamantopoulos (1996), "The Link between Green Purchasing Decisions and Measures of Environmental Consciousness," European Journal of Marketing, 30 (5), 35-55.

Scott, David and Fern K. Willits (1994), "Environmental Attitudes and Behavior: A Pennsylvania Survey," Environment and Behavior, 26 (2), 239-260.

Shin, J.-W. and M.-C. Shin (2012), "A Segmentation Study of the Green Consumer Based on Self-Concept and Green Consumerism, Journal of Environmental Policy and Administration, 20 (4), 1-36.

Shrum, L. J., John A. McCarty, and Tina M. Lowrey (1995), "Buyer Characteristics of the Green Consumer and Their Implications for Advertising Strategy." Journal of $A^{-}$ vertising, 24 (2), 71-82.

Statistics Korea (2013), Report on the Green Lifestyle Survey, Statistics Korea:Daejeon. Straughan, Robert D. and James A. Roberts (1999), "Environmental Segmentation Alternatives: A Look at Green Consumer Behaviour in the New Millennium," Journal of Consumer Marketing, 16 (6), 558-575.

Sütterlin, Bernadette, Thomas A. Brunner, and Michael Siegrist (2011), "Who Puts the
Most Energy into Energy Conservation? A Segmentation of Energy Consumers Based on Energy-related Behavioral Characteristics," Energy Policy, 39 (12), 8137-8152.

Sweeney, Jillian C., Johannes Kresling, Dave Webb, Geoffrey N. Soutar, and Tim Mazzarol (2013), "Energy Saving Behaviours: Development of a Practice-based Model," Energy Policy, 61, 371-381.

Taylor, Shirley and Peter Todd (1995), "Understanding Household Garbage Reduction Behavior: A Test of an Integrated Model," Journal of Public Policy \& Marketing, 14 (2), 192-204.

Tilikidou, Irene (2007), "The Effects of Knowledge and Attitudes upon Greeks' Proenvironmental Purchasing Behaviour," Corporate Social Responsibility and Environmental Management, 14 (3), 121-134.

Verain, Muriel C. D., Jos Bartels, Hans Dagevos, Siet J. Sijtsema, Marleen C. Onwezen and Gerrit Antonides (2012), "Segments of Sustainable Food Consumers: A Literature Review," International Journal of Consumer Studies, 36 (2), 123-132.

Yam-Tang, Esther P. Y. and Ricky Y. K. Chan (1998), "Purchasing Behaviours and Perceptions of Environmentally Harmful Products," Marketing Intelligence \& Planning; 16 (6), 356-362.

Webster, Jr., Frederick E. (1975), “Determining the Characteristics of the Socially Conscious Consumer," Journal of Consumer Research, 
2 (3), 188-196.

Wiernik, Brenton M., Deniz S. Ones, and Stephan Dilchert (2013), “Age and Environmental Sustainability: A Meta-analysis," Journal of Managerial Psychology, 28(7/8), 826-856.
Zimmer, Mary R., Thomas F. Stafford, and Marla Royne Stafford (1994), "Green Issues: Dimensions of Environmental Concern," Journal of Business Research, 30 (1), 63-74. 